\title{
The Influence of Demographic Variables on University Students' Adjustment in North Jordan
}

\author{
Mohd Aderi ${ }^{1}$, Malek Jdaitawi ${ }^{2}$, Noor Azniza Ishak ${ }^{3}$ \& Farid Jdaitawi ${ }^{4}$ \\ ${ }^{1}$ School of Faculty Education, Universiti Kebangsaan Malaysia, Malaysia \\ ${ }^{2}$ School of Preparatory Year and Supporting Studies, University of Dammam, Dammam, Saudi Arabia \\ ${ }^{3}$ School of Social Science, Utara University, Kedah, Malaysia \\ ${ }^{4}$ Ministry of Education, Amman, Jordan \\ Correspondence: Mohd Aderi, School of Faculty Education, Universiti Kebangsaan Malaysia, Malaysia. E-mail: \\ aderi7472@gmail.com
}

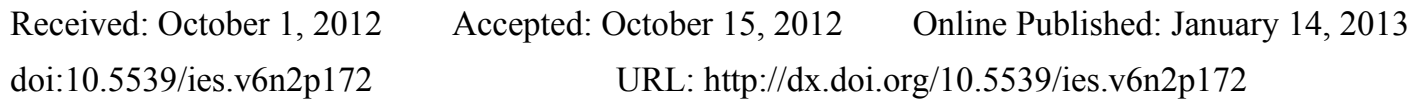

\begin{abstract}
The main aim of the present study is to investigate the student university adjustment particularly the determination of the adjustment level of first year university students in Jordan. The three domains are namely overall college adjustment, domain of social adjustment, and academic adjustment. In addition, in this analysis, gender, age, types of university differences adjustment are evaluated. 244 first year students participated in this study and frequencies, descriptive statistics, independent t-test, and ANOVA are used in the study. The results of the study reveal that university students have a generally moderate adjustment level despite the indication that students have some difficulties in their social and academic factors.
\end{abstract}

Keywords: adjustment, demographic variables, university, students', North Jordan

\section{Introduction}

Literature review reveals that students experience an adjustment period after their entrance into the institution of higher education. Student adjustment includes academic, social and personal-emotional adjustment which relates to experiences such as developing and maintaining goals, expectation, identities, roles, and social networks, as well as student attrition (Baker \& Syrik, 1999, Jdaitawi, Ishak, Taamanh, Gharaibah, \& Rababah, 2011).

Generally speaking, majority of first year students have stated that transition to college happens to be the most stressful adjustment phase in their lives. Additionally, several studies have supported and investigated the level of adjustment among first year students, and reported that many students faced challenges during their transition from high school to university (Thurber \& Walton, 2012; Abdallah, Elias, Muhyddin, Uli, 2009; Winter et al., 2007). Abdallah et al. (2009) carried out a study involving first year university students and the findings revealed that a number of the university students scores low and moderate level of adjustment which they failed to continue on to the second year. Along similar lines, according to Baker and Syrik (1999), the ability of a student to successfully adjust to college is related to a positive college experience, whereas unsuccessful adjustment is related to negative college experience. Important factors relating to transition adjustment includes academic, social support, social adjustment, emotional adjustment, and university services provided to students in their transition as well as student's characteristics.

Grounded theory on student's attachment and adjustment to college has maintained that transition to college can be a stressful experience for many students (Tinto, 1996; Baker \& Syrik, 1999; Pascarella \& Terenzini, 2005). Several students in their transition to university still encounter difficulties related to personal, interpersonal, and academic challenges. However, it is generally believed that learning to study in a university like studying in a new environment normally has some challenges as learning to live in a new culture. Given this fact, many first year students cannot adjust themselves appropriately and in a timely way to suit their novel environments, and personal living arrangement. In other words, they do not know how to live student's lives, learn academic tasks effectively, and how to develop learning habits for their new academic environment (Smith \& Renk, 2007; Paker, Summerfeldt, Hogan \& Majeski, 2004). 
Along these lines, researchers are curious to understand the factors relating to the students' adjustment at college level as well as the factors that make students fail to retain to their second year. For instance, McGhee and Mangrum, (2007) states that social and emotional problems and anxiety during adolescents stage could lead to adjustment problems. Additionally, personal and social factors as well as cognitive factors such as creative thinking, critical thinking, and decision making have also been found to be effect directly and indirectly in successful student adjustment (Goleman, 1998; Mavroveli, Petrides, Sangareau \& Furnham, 2009). Researchers confirmed that individual factors may impact student adjustment (Martin et al, 1999; Barefoat, 2004). Moreover, researchers (Enochs \& Ronald, 2006; Abdallah et al., 2009) found gender differences in the student's adjustment and found male students to possess better adjustment levels than female students. Furthermore, age also play an important factor for successful student's adjustment as Grebennikov \& Skaines (2009) maintain that there are differences between students adjustment based on their age; elder students adjust less as compared to younger students.

\section{Brief History on Jordan Higher Education System}

In the context of Jordan, the educational system has gone through transitions of monumental development and progress. Ever since the 1920s, the country undertook the responsibility of the development of a comprehensive and high-quality system for its citizens' development. Those residing in poor and remote areas were given the opportunity for education through the construction of schools. Owing to the belief that basic education is more important than higher education in Jordan, the literacy levels and the level of enrolment have been enhanced. As a result, Jordan has succeeded in achieving the international standards of education and the country is looking forward to tackle challenges in the future.

Jordanian society is characterized as comprising of mostly younger generation as evidenced by the fact that $42.2 \%$ of students are below 14 , and $13.4 \%$ are between 15-29 years of age. Based on the report by the Ministry of Higher Education (2010), the number of students enrolled in Higher Education Universities in Jordan for the year 2009/2010 is 225,602 students. From this total number of students, 164,174 students are registered in the Universities of Ministry of Education while the remaining 61,428 students, study in private universities. This evidences that a majority of Jordanians study in higher education institutions. The Ministry of Higher Education in Jordan provides educational opportunities for students whether in public or private universities. It is notable that $24 \%$ of the total student population attending universities comprises of first year students. Statistical reports drawn up by the Ministry of Higher Education (2010) shows that 40, 742 students are registered in public universities while 13,979 attend private universities for the year 2009/2010.

\section{Adjustment in Learning Environment in Jordan}

The Jordan society is a conservative with strong family ties. Religion and culture play a major role in the formation of their world views. Fortunately, one of the Jordan's population's characteristics is its youth population based on the huge number of youth in the country. It assumed that most university students in Jordan are adolescents and young adults between the ages of 18-30

years. Being in their late adolescents and late adult, and during the transition period to university many problems confront them including physical, social, academic, and emotional adjustment.

According to students' university statistics conducted from two universities in Jordan, $19.5 \%$ of first year students drop out of their university (Al-Yarmouk, Jadara University, 2010). The adjustment issues faced by first year university students are found to be related to academic problems such as difficulty in coping with the requirements of their course, overcrowding in classrooms, difficulty in using library services, and difficulty in dealing with lecturers. Besides these, some students also face social problems such as interaction with faculties and lecturers and other university members, and the variation between students age in universities have also posed some problems for the students. For these reasons, universities should strive to prepare some social activities to reduce the number of students who fail to adjust adequately to college life.

A Majority of the existing literature on the topic has explored the construct of adjustment among university students in certain countries except Jordan where no existing study regarding this construct exist. Therefore, the current study is dedicated to the exploration of the adjustment experience among first year students in public and private universities in Jordan. It also expounds on the importance of social demographics such as gender, age, and type of university that have been considered as factors that may be influencing Jordanian students' adjustment to their universities. Specifically, the present study aims to explore the social and academic adjustment level among first year university students in Jordan, to find out the relationship between social adjustment and their academic adjustment, and to identify the individual differences in some personal and social factors such as gender, age, type of university. 


\section{Objective of the Study}

The overall objective of this study is to look at the level of adjustment among Jordanian university students. The objectives of the study are as follow:

- To identify the level of adjustment among Jordanian University Students.

- To determine the different levels of students' adjustment based on students gender.

- To look at the different levels of adjustment based on students' age groups.

- To identify the different levels of adjustment based on university type.

\section{University Adjustment}

Arkoff (1968) has coined the construct of adjustment defining university adjustment in terms of college achievement which covered student's academic achievement and personal growth. The term college adjustment is usually concerned with the issues of maladjustment in areas such as academic performance, psychological distress, persistence to degree completion retention, and interaction with others (Ishak, 2005; Jdaitawi, 2011; Baker, Syrik, 1999). Tinto (1996) described two major areas when considering the broad topic of overall college student adjustment: academic factor, social/environment factor. Included in the academic adjustment are factors such as establishing social relationship, and involvement in university activities which can also help students to succeed in their transition period. Baker and Syrik (1999) have categorized students' university adjustment into four demands namely academic adjustment, social adjustment, personal-emotional adjustment, and institutional attachment.

Despite several studies reveal that most first year students have trouble adjusting and maintained that this adjustment is linked to some personal and social factors in individual adjustment, there is no study that investigated which variables contribute to Jordanian university students adjustment. A study of adjustment, particularly in Jordan, is of significance as it can present practical information regarding the factors affecting student adjustment, and may provide knowledge for additional understanding of university students characteristics in Jordan. In addition, adjustment to university has been associated with various negative emotions and behavior. Therefore, it is of a great value to explore the predictors of adjustment and find affective way to reduce adjustment problem among university students.

\section{Methodology}

The data is gathered from a convenience sample consisting of 250 first year students from two higher learning education universities in Irbid, located in north Jordan. There are $125(50 \%)$ male and $125(50 \%)$ female students participating in the survey. The age includes three categories - 94 students (37.6\%) below 20, 94 students (37.6\%) range from 21-25, and the third category, 62 (24.8\%) students above 26. 135 (54\%) students come from public university and $115(46 \%)$ students from private university.

The study uses a self report questionnaire as the instrument to collect data, which comprises of two parts: demographic information, and student adjustment to college questionnaire. Demographic information has been developed for this study based on research sample. Student adjustment is measured by using the instrument developed by Baker and Syrik (1999) to measure student adjustment to college. Baker and Syrik (1999) established high reliability coefficient alpha for the SACQ ranging from .92 to .95 . The scale comprised of 67 items focusing on adjustment components that contribute to student adjustment to their university. Those components are (1) social adjustment, (2) academic adjustment, (3) personal-emotional adjustment, and (4) goal commitmentlinstitutional attachment. Students are required to respond on the nine Likert scale ranging from 1 (doesn't apply to me at all) to 9 (apply very closely to me). For this study two subscales have been used to evaluate student adjustments which are social adjustment and academic adjustment. The former refers to student's satisfaction with the social aspects of college while the latter refers to meeting the educational goals and demands innate to the university experience. 7 items are negative for social adjustment subscale and are coded positive, and 10 items are negative for academic adjustment subscale. Furthermore, two items have been deleted from the social adjustment subscale because most of the students participated in this study are staying with their parents. These items are: I enjoy having a college dormitory and I am getting along very well with my roommate at college. The score in social adjustment subscale range from 17 to 123 and from 22 to 198 for academic adjustment subscale. The Cronbach's alpha for the two subscales range from .828 to .852 and the combination of these scales is .862 . 


\section{Results}

A first assumption is conducted to check the normality and outlier and then data are analyzed Descriptive statistics analysis identified 6 cases as non-normal cases and are dropped out from the next analysis. Data is furthered analyzed to identify the adjustment level among first students based on two subscales. The researchers made modified adjustments on the level based on guidelines provided by the authors. Two subscales are divided into three categories (high, moderate, low) based on the mean total scores. Table 1 indicates the level of adjustment as well as the level of each subscale. Results indicated that $51.63 \%$ of the students' overall adjustment is at the moderate level, while $36.88 \%$ obtained a low level of overall adjustment, and only $11.47 \%$ are found to be in the high level of overall adjustment. Regarding social adjustment, subscale results indicate that $52.04 \%$ obtained moderate level, and $30.33 \%$ of respondents obtained low level, while $17.63 \%$ obtained high social adjustment level. Also results indicated that $35.63 \%$ of respondents have low level of academic adjustment, $49.27 \%$ obtained moderate academic adjustment level, and $15.20 \%$ of respondents are found in the high level. These results indicated that the most of first year students have adjustment problems as shown in table 1 .

Table 1. Student adjustment level scores

\begin{tabular}{|c|c|c|c|c|c|c|c|c|c|}
\hline \multirow[t]{2}{*}{ Scale } & \multicolumn{3}{|c|}{ Low } & \multicolumn{3}{|c|}{ Moderate } & \multicolumn{3}{|c|}{ High } \\
\hline & Score & $f$ & $\%$ & Score & $f$ & $\%$ & Score & $f$ & $\%$ \\
\hline $\begin{array}{c}\text { Overall } \\
\text { Adjustment }\end{array}$ & Below 159 & 90 & 36.88 & $160-220$ & 126 & 51.63 & Above 220 & 28 & 11.47 \\
\hline $\begin{array}{c}\text { Social } \\
\text { Adjustment }\end{array}$ & Below 65 & 74 & 30.33 & $66-95$ & 127 & 52.04 & Above 96 & 43 & 17.63 \\
\hline $\begin{array}{c}\text { Academic } \\
\text { Adjustment }\end{array}$ & Below 85 & 87 & 35.63 & $86-126$ & 120 & 49.27 & Above 126 & 37 & 15.20 \\
\hline
\end{tabular}

The Difference of adjustment level based on student's gender: An independent sample f-test is used to compare the mean scores of adjustment, for male and female first year university students. The difference of adjustment level based on student's gender from an entire view is shown in Table 2. Analysis of f-test shows no significant difference on the level of adjustment among the male students and female students, $F=.391(0.532 ; p>0.05$. In other words, the differences of the two groups are equal. Further analysis is made to compare the student's academic and social adjustment between male and female students. Results of $F$-test indicate a difference between male and female students on social adjustment. The significant 2-tailed value of $r$-test is $t(-.023)(.985$, $p=.000$, that is $p$-value less than the alpha value .05 . indicating female students $(\mathrm{M}=4.675)$ possess better social adjustment than male students $(\mathrm{M}=4.671)$. However, result also indicates no differences between male and female on academic adjustment scale $(\mathrm{F}=.488)=.486, \mathrm{p}>.05$. Table 2 shows the differences of adjustment level based on gender.

Table 2. T-Test result differences of gender on adjustment, social adjustment, and academic adjustment

\begin{tabular}{lllllllll}
\hline Factor & Gender & $\mathbf{N}$ & $\mathbf{M}$ & SD & $\begin{array}{l}\text { Mean } \\
\text { Diff }\end{array}$ & f-value & df & $\begin{array}{l}\text { Sig- } \\
(2 \text {-taild })\end{array}$ \\
\hline ADJ & Male & 124 & 4.48 & .931 & -.147 & .532 & 242 & .391 \\
SA & Female & 120 & 4.63 & .916 & & & & \\
AA & Male & 124 & 4.671 & 1.198 & -.034 & .985 & 242 & .000 \\
& Female & 120 & 4.675 & 1.176 & & & & \\
& Male & 124 & 4.353 & 1.109 & -.245 & .486 & 242 & .488 \\
& Female & 120 & 4.599 & 1.107 & & & & \\
\hline
\end{tabular}

The Difference of adjustment level based on student's age: A one way ANOVA and post-hoc tukey test are used to compare the mean scores on adjustment based on age groups of first year university students. The difference 
of adjustment level based on the student's age from an entire view is shown in Table 3. Analysis of ANOVA test shows that there is a significant difference in the level of adjustment among age groups students, $F=3.310(.038$; $p>0.05$. This means there is a difference between age groups regarding level of adjustment. Further analysis is made and post-hoc tukey is used to compare the differences between age groups and results show that the younger students have better adjustment as compared to elder ones. Table 4 presents the results of descriptive statistics differences between students based on their ages. The table shows mean scores for groups based on adjustment level, group $1(\mathrm{M}=4.77, \mathrm{SD}=.835)$, group $2(\mathrm{M}=4.44, \mathrm{SD}=1.03)$, and group $3(\mathrm{M}=4.46, \mathrm{SD}=.834)$. However, further analysis have made for subscales and results indicate there significant differences between age groups on academic adjustment scale $(\mathrm{F}=4.792)=.009, p>.05$. Furthermore, results also indicate no differences between age group based on social adjustment subscale $(\mathrm{F}=.871)=.420, p>.05$.

Table 3. ANOVA Results of adjustment based on age groups variable

\begin{tabular}{llllll}
\hline Adjustment & SS & DF & MS & F & Sig \\
\hline Between group & 5.561 & 2 & 2.780 & 3.310 & .038 \\
Within group & 202.442 & 241 & .840 & & \\
Total & 208.003 & 243 & & & \\
\hline
\end{tabular}

Table 4. Descriptive statistics on adjustment scale among age groups

\begin{tabular}{lllll}
\hline Adjustment & Mean & Sta. Deviation & Minimum & Maximum \\
\hline Age 1 (18-20) & 4.77 & .83 & 2.84 & 6.59 \\
Age 2 (21-25) & 4.44 & 1.63 & 2.00 & 7.16 \\
Age 3 (Above 25) & 4.46 & .83 & 2.92 & 6.08 \\
Total & 4.55 & .925 & 2.00 & 7.16 \\
\hline
\end{tabular}

The Difference of adjustment level based on the type of university: An independent sample f-test is used to compare the mean scores on adjustment of students based on type of their universities. The difference of adjustment level of student based on the type of university from the entire view is shown in Table 5. Analysis of f-test shows that there is a significant difference level of adjustment between students who study at public university and students who study at private university, $F=.10 .827(.001 ; p>0.05)$. In other words, the differences between the two groups are not equal. Result in table 5 show that there are significant differences in the mean adjustment scores for public university students $(\mathrm{M}=4.60, \mathrm{SD}=.818)$ and private university students $(\mathrm{M}=4.501, \mathrm{SD}=1.03)$. Comparison of the two mean scores suggests that Public University Students have better adjustment levels than Private University Students.

Table 5. T-Test result differences of adjustment based on type of university

\begin{tabular}{lllllllll}
\hline Factor & Type of University & N & M & SD & $\begin{array}{l}\text { Mean } \\
\text { Diff }\end{array}$ & f-value & df & $\begin{array}{l}\text { Sig. } \\
\text { (2-taild) }\end{array}$ \\
\hline ADJ & Public & 130 & 4.60 & .818 & .100 & 10.827 & 242 & .001 \\
& Private & 114 & 4.50 & 1.03 & & & & \\
\hline
\end{tabular}

\section{Discussion and Conclusion}

For the purpose of assessing the adjustment problems of first year university students, the aims of the study is to explore the adjustment level among first year university students, and to see demographic variable influencing the adjustment of the students. The results of the study reveal that university students have a generally moderate adjustment level despite the indication that students have some difficulties in their social and academic factors. Additionally, results indicate that majority of the students possess low to moderate level of social adjustment subscale $(82.37 \%)$, as well as $(84.89 \%)$ low to moderate level of academic adjustment subscale $(84.89 \%)$. These results are consistent with previous studies regarding first year university students' adjustment problems at their 
universities (Tinto, 1996; Abdallah., 2009). Jemal (2012) in his study of 204 college students, found that 50\% of universities students have adjustment problems.

Moreover, the results show that demographic characteristics are related to university adjustment, although no significant differences are found between male and female students' adjustment level which is inconsistent with previous studies (Abdallah et al., 2009). This insignificant finding may be attributed to the changing female roles in the society coupled with the greater leadership opportunities that are now available for women compared to the past. In the case of ages, younger students are revealed to have better adjustment levels as compared to elder students as evidenced by Grebennikov and Skaines (2009). Furthermore, the reason of the higher scores of younger students than elder students is due to the fact that elder students generally have a hard time making friends and becoming involved in university life. Only a limited number of studies are carried out and related the differences between student's adjustment at public university and private university and the present study's results reveal that there are differences between student's adjustment at public university and private university as public university students have better adjustment levels than private university students, this is because to students at public university have a wider area of exposure to the experience through interaction with other students from different background and cities.

\section{Limitation and Recommendation of the Study}

In higher education, the evaluation of student's adjustment in the university has been recently considered as a major focal point. Based on several studies' reports on the issue of a large number of first year university students leaving the university before obtaining their degree, there is an encouragement from the previous studies to identify adjustment level as well as individual differences related to adjustment in order to create specific training programs related to sub group students to smoothen student's adjustment in the university. Hence, the present study is the first of its kind in investigating university student's adjustment. The aim of the study is to explore the adjustment level of students and variables related to students demographic in Jordan. The researcher urges more research to be dedicated in the exploration of adjustment level as well as the variables that can influence student's adjustment. Overall, this study demonstrated increase understanding of adjustment phenomena among university students in Jordan. Although, the results of the current study are interesting, several limitation may have influenced the results. the first one being the sample of the study as the study used convenience sampling consisting of first year university students. Through the use of a convenience sample, the researcher limits the ability to generalize the results of the study into a broader sample (Fisher et al., 2002). In addition, the sample may not represent a bigger population because it is taken from only two universities in Northern Jordan disregarding others. In other words, generalization across geographical as well as demographical areas is not confirmed. Second, due to the fact that quantitative data is taken through self-report measures, there is ample chance that participants manipulated their answers for several reasons. They might have gotten bored with the test battery and chose answer to get over it quickly, to satisfy the researcher; therefore, they might have voluntary or involuntary chosen answers which are not their true experience. As for recommendations for future research, this study recommends and proposes the following: Firstly, based on the limitation of the current study, ample opportunities are present for future research while using the same design and framework. Future researches should look into and study all Jordanian public and private universities. Secondly, the time period of the current study is significant to the outcome therefore, this study recommends that future research should appropriate more time for similar studies. Although, the study made effective use of quantitative methodology but recommends that future researches use qualitative methods to shed a light on student's perception of the transition to the university. Moreover, the findings of the study can assist in guiding universities' presidents in the development of policies as well as programs aiming to build the strength that can help students to cope with adjustment problems.

\section{References}

Abdallah, M. C., Elias, H., Muhyddin, R., \& Uli, J. (2009). Adjustment Among First Year Students in a Malaysian University. European Journal of Social Science, 8(3).

Arkoff, A. (1968). Adjustment and Mental Health. USA: McGraw-Hill-Book Company.

Baker, R. W., \& Siryk B. (1999). SACQ: Student adaptation to college questionnaire manual (2nd. Ed.). Los Angeles: Western Psychological Services.

Barefoot, B. O. (2004). Higher Education's Revolving Door: Confronting the Problem of Student Drop Out in U.S. Colleges and Universities. Open Learning, 19(1), 9-18. EBSCOhost database. http://dx.doi.org/10.1080/0268051042000177818 
Enochs, W. C., \& Roland, C.B. (2006). Social adjustment of college freshmen: the importance of gender and living environment. College Student Journal.

Fisher, A. A., Foreit, J. R., Laing, J., Stoeckel, J., \& Townsend, J. (2002). Designing HIV/AIDS intervention studies: An operations research handbook. The Population Council Inc. Retrieved July 23, 2009, from http://www.popcouncil.org/pdfs/horizons/orhivaidshndbk.pdf

Goleman, D. (1998). Working with Emotional Intelligence. New York: Bantam.

Grebennikov, L., \& Skaines, I. (2009). University of Western Sydney Students at Risk: Profile and Opportunities for Change. Journal of Institutional Research, 14, 58-70.

Jdaitawi, M., Ishak, N., Taamneh, M., Ghataibeh, M., \& Rababah, O. (2011). The effectiveness of Emotional Intelligence Training Program on Social and Academic Adjustment among First Year University Students. International Journal of Business and Social Science, 2(24), 251-258.

Jemal, J. (2012). Assessing Major Adjustment Problems of Freshman Students in Jimma University. Ethiop.J. Educ. \& Sc., 7(2), 1-14.

Martin Jr.,W. E., Swartz, J. L., \& Madson, M. (1999). Psychosocial Factors that Predict the College Adjustment of First-Year Undergraduate Students: Implications for College Counselors. [Electronic version]. Journal of College Counseling, 2(2), 121-133. http://dx.doi.org/10.1002/j.2161-1882.1999.tb00150.x

Mavroveli, S., Petrides, K. V., Sangareau, Y., \& Furnham, A. (2009). Exploring the Relationships between Trait Emotional Intelligence and Objective Socio-Emotional Outcomes in Childhood. British Journal of Educational Psychology, 79, 259-272. http://dx.doi.org/10.1348/000709908X368848

McGhee, R. L., \& Mangrum, L. (2007). McGhee Mangrum Inventory of school adjustment. Examiners manual pro.ed: Texas.

Ministry of Higher Education and Scientific Research. (2010). Jordan higher education statistical summary. Retrieved from www.mohe.gov.jo

Noor Azniza, I. (2005). Different effects of REBT brief group intervention and behavior brief group intervention toward maladjustment. Unpublished Doctoral Dissertation. University Science Malaysia.

Parker, J. D. A., Summerfeldt, L. J., Hogan, M. J., \& Majeski, S. A. (2004). Emotional intelligence and academic success: Examining the transition from high school to university. Personality and Individual Differences, 36, 163-172. http://dx.doi.org/10.1016/S0191-8869(03)00076-X

Pascarella, E. T., \& Terenzini, P. T. (2005). How College Affects Students. San Francisco, CA: Jossey-Bass.

Smith, T., \& Renk, K. (2007). Predictors of academic-related stress in college students: An examination of coping, social support, parenting, and anxiety [Electronic version]. NASPA Journal, 44(3), 405-431.

Thurber, C., \& Walton, E. (2012). Homesickness and Adjustment in University Students. Journal of American College Health, 60(5), 1-5. http://dx.doi.org/10.1080/07448481.2012.673520

Tinto, V. (1993). Leaving college: Rethinking the Causes and Cures of Student Attrition (2nd.ed.). Chicago: University of Chicago Press.

Tinto, V. (1996). Reconstruction the first year of college [Electronic version]. Planning for Higher Education, 25(1), 1-6.

Wintre, M. G., \& Bowers, C. D. (2007). Predictors of Persistence to Graduation: Extending a Model and Data on the Transition to University Model [Electronic version]. Canadian Journal ofBehavioural Science, 39(3), 220-234. http://dx.doi.org/10.1037/cjbs2007017 